\title{
ОРГАНИЗАЦИЯ РАЗВИВАЮЩЕЙ ПРЕДМЕТНО- ПРОСТРАНСТВЕННОЙ СРЕДЫ ДЛЯ ДЕТЕЙ РАННЕГО ВОЗРАСТА В СЕМЬЕ И ОБРАЗОВАТЕЛЬНОМ УЧРЕЖДЕНИИ
}

\section{CREATING A DEVELOPING SUBJECT AND SPATIAL ENVIRONMENT AT HOME AND IN ORGANIZATIONS FOR CHILDREN OF EARLY AGE}

\section{O. Yugova}

A. Mironova

E. Rykova

Summary: In the article are revealed peculiarities in formation children's leading activities in infantile and early age, characterized environmental approach in general and specialists in choosing suitable subject - playing material according to methodical aims and task taking into account age. In the article is described the specific creating subject developing environment for children with special needs of different categories. Also offered recommendations for zoning premises for classes with children on different kinds of activities.

Keywords: children development, early age, subject activity, play, developing subject and spatial environment, family upbringing, special healthcare needs and disabilities

\author{
Югова Олеся Вячеславовна \\ к.n.н., доцент, ГАОУ ВО МоскОвский городской \\ педагогический университет \\ kor.ped@inbox.ru \\ Миронова Ангелина Валерьевна \\ старший преподаватель, ГАОУ ВО Московский \\ городской педагогический университет \\ moya_angelina@mail.ru \\ Рыкова Елена Алексеевна \\ Ассистент, ГАОУ ВО Московский городской \\ педагогический университет \\ elena-rykova@mail.ru
}

Аннотация: В статье раскрываются особенности формирования ведущей деятельности детей младенческого и раннего возраста, характеризуется средовой подход в системе общего и специального образования, даются рекомендации для родителей и специалистов по выбору адекватного предметно-игрового материала, исходя из различных методических целей и задач, а также требований возраста. В статье описывается специфика создания предметно-развивающей среды для детей с ограниченными возможностями здоровья разных категорий. Также предложены рекомендации по зонированию помещения для занятий с детьми по различным видам деятельности.

Ключевые слова: развитие ребенка, ранний возраст, предметная деятельность, игра, предметно-развивающая среда, семейное воспитание, ограниченные возможности здоровья.

ращали внимание на то, что в первые годы жизни приоритетным и базисным для интеллектуального развития ребенка является сенсорное развитие и формирование представлений о свойствах предметов. Жажда познания окружающего мира в сочетании с потребностью в эмоциональном общении со взрослым определяет поведение ребенка раннего возраста.

В период раннего возраста (1-3 лет) ведущей деятельностью становится предметно-орудийная, направленная на овладение социальным способом использования предмета, а социальная ситуация развития ребенка в этом возрасте выглядит следующим образом: «ребенок - ПРЕДМЕТ - взрослый». И от того, какой будет окружающая ребенка предметно-игровая среда, в определенной степени зависит его психическое развитие.

Как отмечает Д.Б. Эльконин, развитие предметных действий у детей раннего возраста ведется по двум направлениям: от совместного со взрослым до самостоятельного исполнения развития действий; развитие 
средств и способов ориентации самого ребенка в условиях осуществления предметного действия [6].

В процессе предметно-манипулятивной игры дети приобретают знания об окружающем мире, приобретают новые моторные и двигательные навыки, знакомятся с предметами и осваивают действия с ними. Кроме того, в предметной игре развивается интеллектуальная сфера ребенка, зрительное, слуховое и другие виды восприятия. В совместной игровой деятельности со взрослым у ребенка раннего возраста происходит активное речевое развитие, обогащение лексического строя речи. Игра является источником положительных эмоций, радости, удовольствия. С помощью взрослого маленький ребенок в процессе игры развивает коммуникативные навыки, учится общаться со сверстниками, контролировать свои действия. На этом этапе в играх проявляются возрастные и индивидуальные особенности детей [5].

Познавательно-исследовательская деятельность, по описанию Е.О. Смирновой, это вид детской активности, направленный на непосредственное, опытное познание окружающей действительности - предметов, явлений, их связей и закономерностей (манипулирование, предметная деятельность, экспериментирование). Познание окружающего в первые годы жизни, наравне с общением с близкими взрослыми, - главная задача и движущая сила детского развития.

Уже с 3-4 месяцев жизни ребенок начинает проявлять исследовательский интерес к окружающим его предметам, в том числе живым объектам (членам семьи или животным). Эти действия направлены на изучение неспецифических свойств предмета. В процессе манипулирования происходит удовлетворение потребности в сенсомоторных впечатлениях, которые являются базой развития в этом возрасте. Универсальной игрушкой является погремушка, а подбор ее происходит, исходя из соображений безопасности и удобства для захвата и манипулирования. Также в этот период используются подвески, растяжки и мобили, которые побуждают ребенка дотягиваться до них и наблюдать за движением. До тех пор, пока ребенок не может осуществить захват предмета, наличие игрушек, особенно большого их количества, представляет сомнительное значение. Наиболее активные манипуляции начинают совершаться ребенком тогда, когда он становится способен садиться и удерживать это положение, а его освобожденные от функции опоры руки готовы к исследованию предметов.

Предметная деятельность - вид познавательно-исследовательской активности, направленный на познание специфических свойств предмета. Главной, ведущей, деятельностью она становится к 1 году, когда ребёнок приобретет стремление к самостоятельности и независимости, и в то же время взрослый становится для ребёнка образцом культурных действий с предметами. Во время совместной игры ребёнок одновременно удовлетворяет и потребность во внимании взрослого, и желание познавать окружающий его предметный мир. Игрушки для предметной деятельности: пирамидки, вкладыши - матрешки, стаканчики и прочие предметы для соотносящих действий, каталки и другие динамические игрушки, наборы объемных геометрических фигур разного цвета и величины, обычные предметы обихода, природный материал.

Экспериментирование - это вид познавательно-исследовательской деятельности, направленный на изучение свойств, связей и закономерностей окружающего мира. К ним относятся природные материалы (песок, вода и др.), конструкторы, лупа, весы, калейдоскоп, простые механизмы, головоломки и т.д.

Продуктивная деятельность - вид детской активности, направленный на создание какого-нибудь продукта, которым может явиться конструкция, рисунок, аппликация и т.д. Зачатки продуктивной деятельности встречаются уже в раннем возрасте. Наборы для детского творчества обязательно должны оставлять простор детскому воображению. Природный и бросовый материал отлично применимы при создании творческих продуктов.

Ребенок первых лет жизни сталкивается не только с предметами-орудиями. С первых месяцев жизни его окружают предметы, специально предназначенные для детей и требующие иных способов действия - игрушки. Если действия с предметами-орудиями (ложкой, чашкой, лопаткой и пр.) требуют определенных фиксированных способов действия, то с игрушками он волен распоряжаться по своему усмотрению, они предполагают полную свободу ребенка. Предметно-практическая деятельность всегда направлена на какой-то результат и регулируется его получением, а действия с игрушками не предполагают оного. В начале второго года жизни игрушка выступает для ребенка в том же качестве, что и любой другой предмет, с которым можно манипулировать и осуществлять неспецифические действия, а игра является процессуальной, не имеет сюжета, воображаемой ситуации, в ней не используются предметы-заместители, дети не берут на себя роли. Л.С. Выготский называл процессуальную или предметную игру квазиигрой, поскольку для самого ребенка она еще не стала игрой [4].

В раннем возрасте приоритетным для интеллектуального развития является сенсорное воспитание, обогащение чувственного опыта, формирование представлений о свойствах предметов. Жажда познания окружающего мира в сочетании с потребностью в эмоциональном общении со взрослым определяет поведение ребенка первых лет жизни. Обучение возможно и необходимо не только в дошкольных образовательных учреждениях, 
где ребенок находится в группе сверстников и где с ним проводятся регулярные систематические развивающие занятия. Очень многому его могут и должны научить родители и другие члены семьи в повседневных бытовых ситуациях, во время выполнения режимных моментов.

Когда ребенок овладевает способностью самостоятельно активно передвигаться, он начинает все полнее и шире познавать окружающий мир, изучать и исследовать объекты, которые находятся в пределах его досягаемости - игрушки и предметы домашнего обихода. Ребенок наблюдает за тем, как взрослые действуют с теми или иными предметами, выполняют работу по дому, он усваивает этот опыт, старается подражать. В процессе предметной и игровой деятельности ребенок познает окружающий мир, знакомится с различными свойствами предметов; формируются восприятие, мышление, речь, внимание, память, воображение ребенка; закладываются основы положительного взаимодействия со сверстниками [2].

Современная ситуация в российском дошкольном образовании характеризуется достаточно четким пониманием специалистами значимости создания предметно-развивающей среды развития детей, выделяются различные подходы и принципы ее организации (О.В. Артамонова, С.Л. Новоселова, В.А. Петровский, Н.Н. Поддъяков, М.Н. Полякова, С.А. Смирнов и др.). Научные разработки в этом направлении актуализировали поиск путей практического решения проблемы в условиях дошкольных образовательных учреждений, семьи и других институтов социализации личности [3].

Средовой подход является крайне важным в системе специального образования. Структура развивающей среды в условиях ранней помощи детям с ОВ3 представляет собой единство и взаимодействие трех полифункциональных уровней: программно-методического, коммуникативно-развивающего, коррекционно-педагогического [2].

Среда является важным фактором развития, воспитания и образования ребенка. Выделяют микро- и макросреду, а также их составляющие. Микросреда - это внутреннее оформление помещений (дошкольной образовательной организации или квартиры, где живет ребенок). Макросреда - это ближайшее окружение детского учреждения (участок, ближний сквер, парк) [1].

В современной специальной литературе специфику развивающей предметно-пространственной среды для детей с ОВ3 в основном рассматривают в контексте образовательной организации. Это связано с введением Федерального образовательного стандарта дошкольного образования и выделением в разделе III пунктов 3.2.2. и 3.4.4 по созданию специальных условий обучения, вос- питания и развития детей с ОВ3. Требования к безопасности предметно-пространственной среды определены Постановлением Главного государственного санитарного врача Российской Федерации от 15 мая 2013 г. № 26 «Об утверждении СанПиН 2.4.1.3049-13 «Санитарно-эпидемиологические требования к устройству, содержанию и организации режима работы дошкольных образовательных организаций».

Одной из важных задач специалистов сопровождения является создание в группе дошкольной образовательной организации адекватной возрасту и особенностям развития детей предметно-пространственной среды, которая будет способствовать их оптимальному развитию, компенсации и социализации. Также педагоги и психологи должны давать рекомендации родителям ребенка по созданию соответствующей среды дома, чтобы ее влияние было непрерывным и комплексным. Среда в данном контексте включает помещение, в котором живет ребенок, предметы быта, игрушки, взаимодействие с близкими, что оказывает огромное влияние на его развитие и является фактором коррекционно-компенсаторного преодоления нарушений психофизического развития. Все, что окружает ребенка, формирует его психику, является источником его знаний и социального опыта.

Следует предостеречь родителей от предметного перенасыщения игрового и досугового пространства ребенка. Ранний возраст характеризуется непроизвольностью восприятия и внимания, а также слабостью волевых процессов, поэтому для локализации и концентрации внимания нужно, чтобы было меньше отвлекающих факторов, грамотно организованное игровое пространство и рабочее место. Также важно рекомендовать руководствоваться при выборе игрушек и пособий не маркировкой на упаковке, которая, как правило, носит формальный характер в соответствии с безопасностью для того или иного возраста, а тем, какие развивающие и методические задачи она призвана решить с учетом не только психологического возраста ребенка, но и его индивидуальных особенностей [7].

Для разных категорий детей с ограниченными возможностями здоровья имеются определенные особенности организации предметно-развивающей среды.

Для эффективного развития ребенка с нарушением зрения необходимо наличие дома сенсорного уголка, в котором будут находиться: сделанные из разного материала различные звучащие и заводные игрушки; предметы, по своим физическим характеристикам доступные для восприятия, побуждающие ребенка к активным исследовательским действиям, для которых характерна целостность структуры, простота формы, отсутствие излишней детализации, не несущей для объекта логиче- 
скую нагрузку; тактильные рукодельные предметы; рельефнографический иллюстративный материал (книги, панно, карточки, картинки); барельефные изображения, текстурные тактильно-развивающие панели; ручные лабиринты; тактильные дорожки и пр.

Особенности предметно-развивающей среды для детей с нарушением интеллекта заключаются в наличии реальных предметов для рассматривания и обследования различных сенсорных эталонов (формы, цвета и величины); наличие объемных и плоских фигур одних и тех же предметов, складных кубиков и разрезных картинок; материал для развития тактильных ощущений (крупы, орехи, песок и т.д.); музыкальные игрушки; пирамидки, сортеры, матрешки, вкладыши, кубики; реалистичный иллюстративный материал и др.

Для эффективного развития ребенка с нарушением слуха необходимо иметь большое количество звучащих погремушек и игрушек различных частотных характеристик; разнообразные музыкальные инструменты; музыкально-дидактические игры; предметы для рассматривания и обследования различных сенсорных эталонов; картинки, таблички и пособия для изучения пространственных понятий; пирамидки, сортеры, матрешки, вкладыши; разнообразный конструктор; красочные книги и пр.

Предметно-развивающая среда для детей с нарушениями эмочионально-волевой сферы имеет особую специфику: рекомендуется зонирование комнаты (например, выделение зоны для творчества, релаксации, оборудование игровой зоны и др.), расположение атрибутики для соответствующей деятельности в строгом соответствии с привычками ребенка, создание сенсорно обогащенной среды; наличие расписания, алгоритмов деятельности, схем, режима дня в картинках; наличие предметов для развития перцептивных действий, сенсорной сферы, реальных предметов для рассматривания и изучения, простого иллюстративного материала по ознакомлению с природой, окружающим, действиями людей и др.

Особенности предметно-развивающей среды для детей с нарушениями опорно-двигательного апnарата связаны с соблюдением индивидуального ортопедического режима ребенка. В соответствии с рекомендациями врача, определяются правила посадки и передвижения ребенка с использованием соответствующих технических средств. В связи с этим желательно наличие следующих пособий и предметов: тренажеров-панелей для развития двигательных навыков, настенных панелей для эрготерапии, звучащих и музыкальных игрушек, тренажеров для развития моторики, сборно-разборных игрушек, разнообразных бизибордов, различных мячей, сухого бассейна и пр.
Для детей раннего возраста, в том числе с проблемами в развитии, рекомендуется выбирать материалы для развития по всем линиям: социальной, познавательной, речевой и двигательной. Помещение, в котором занимаются дети, должно быть с естественным освещением, легко проветриваемое. Работа должна быть комфортна для детей, следует ограничить отвлекающие факторы, посторонние шумы и звуки.

Создавая развивающее пространство, в котором будут заниматься дети, необходимо учитывать ведущую роль предметно-игровой деятельности. Все игрушки и предметы должны вызывать у детей положительные эмоции, желание их исследовать. Игровой материал должен быть яркий, прочный. Целесообразно разделить помещение для занятий на зоны в соответствии с различными видами деятельности.

- Зона развития общей моторики представляет собой физкультурный уголок, который содержит, например, шведскую стенку; мягкую горку; деревянную горку; сухой бассейн с шариками; качели; мячи различных размеров и т.д.

- В зоне развития мелкой моторики используются предметы и игрушки, разные по форме, величине, цвету, тактильным и звуковым ощущениям, с которыми можно совершать различные манипуляции. Этой же цели служат пальчиковые игрушки, шнуровки, застежки, липучки, пинцеты и т.д.

- Зона продуктивной деятельности. Здесь должен обязательно находиться стол и скамейки для проведения занятий; материалы для рисования, аппликации, лепки и т.д.

- Зона упражнений в практической жизни включает материалы для упражнений с сыпучими материалами (крупа, горох, фасоль) и упражнений с водой. Ребенок учится переливать жидкости из одной емкости в другую, пересыпать крупы ложкой и другими орудиями, мыть предметы и т.д. В процессе этой деятельности происходит совершенствование навыков самообслуживания ребенка.

- Музыкальная зона оснащена фортепиано и различными детскими музыкальными инструментами (бубен, колокольчики, маракасы, трещотки и т.д.). Помимо этого, здесь может располагаться материал для театрализованных игр (ширма, куклы «Би-ба-бо», пальчиковые куклы, музыкальные и звучащие игрушки).

- В зоне сенсорного развития расположено оборудование, разработанное М. Монтессори: «блоки цилиндров», «коричневая лестница», «розовая башня», «цветные таблички», «звуковые цилиндры», «коробочки с запахом», «геометрический комод», «цветные цилиндры», «Доски Сегена» и другие сортеры, рамки-вкладыши, пирамидки разной величины, геометрические головоломки и т.д. 
- Зона развития речи обогащена книгами; наборами картинок и предметов по основным лексическим темам: игрушки, одежда, посуда, мебель, транспорт, овощи, фрукты, животные, птицы; наборами парных картинок, сюжетных картинок и т.д.

Разделение помещения способствует свободному выбору и работе с материалом, взаимодействию с другими детьми, повышению их самостоятельности.

Хочется отметить, что дети первых лет жизни предпочитают играть на полу, поэтому поверхность пола не должна быть холодной и излишне твердой.

Детям с особыми образовательными потребностями может потребоваться специальная мебель и оборудование, адаптированное под их особенности развития (в первую очередь, это касается детей с нарушениями опорно-двигательного аппарата, зрения и слуха). В группе желательно иметь специализированное оборудование для сидения: кресла с подлокотниками или сплошными бортами; валики и мягкие подушки; лавоч- ки - скамейки, которые можно использовать сидящем на полу детям в качестве стола; специальные приспособления для сидения на полу, для поддержки спины детям.

Регулярность, систематичность и последовательность занятий очень важны для достижения положительного результата. Темпы овладения различными умениями и навыками у детей могут варьировать. При планировании занятий следует соблюдать четкую последовательность и поэтапность. Следует дозировать информацию, не перегружать ребенка новыми сведениями и впечатлениями, постепенно усложнять и расширять объем знаний. Один и тот же игровой и дидактический материал может использоваться в самых разнообразных заданиях и с совершенно различными целями и задачами [2].

Использование в работе педагогом широкого спектра разнообразных подходов, способов обучения и развития, материалов и оборудования определяется потребностями и особенностями детей, их предпочтениями и актуальным уровнем психофизического развития.

\section{ЛИТЕРАТУРА}

1. От рождения до школы. Примерная основная общеобразовательная программа дошкольного образования / Под ред. Н.Е. Вераксы, Т.С. Комаровой, М.А. Васильевой. - 2-е изд., испр. и доп. - М.: Мозаика-Синтез, 2011. - 336 с.

2. Приходько 0.Г. Предметно-развивающая образовательная среда для детей первых лет жизни с ограниченными возможностями здоровья. В сборнике: Раннее и дошкольное образование в системе непрерывного сопровождения детей с ограниченными возможностями здоровья. Сборник научных статей по материалам научно-практической конференции. 2017. С. 170-176.

3. Сазонова Н.П. Лекционные и семинарские занятия по дошкольной педагогике / учебное пособие для студентов педагогических факультетов - Барнаул : АлтГПА, 2014. -381 с.

4. Смирнова, Е.О. Детская психология : учебник [Текст] / Е. О. Смирнова. - М.: КНОРУС, 2016. - 280 с.

5. Соколова, А. В. Игры и игрушки для детей раннего и дошкольного возраста: учеб.-метод. пособие / А. В. Соколова. - Нижний Тагил, 2018. - 96 с.

6. Эльконин Д. Психология игры. -- М.: Владос, 1999. - 360 с.

7. Югова 0.В. Формирование ведущей деятельности у детей раннего возраста и роль взрослого в ее становлении. В сборнике: Раннее развитие и коррекция: теория и практика - М., 2016. - с. 326-335.

○ Югова Олеся Вячеславовна (kor.ped@inbox.ru ), Миронова Ангелина Валерьевна (moya_angelina@mail.ru),

Рыкова Елена Алексеевна (lena-rykova@mail.ru).

Журнал «Современная наука: актуальные проблемы теории и практики» 